
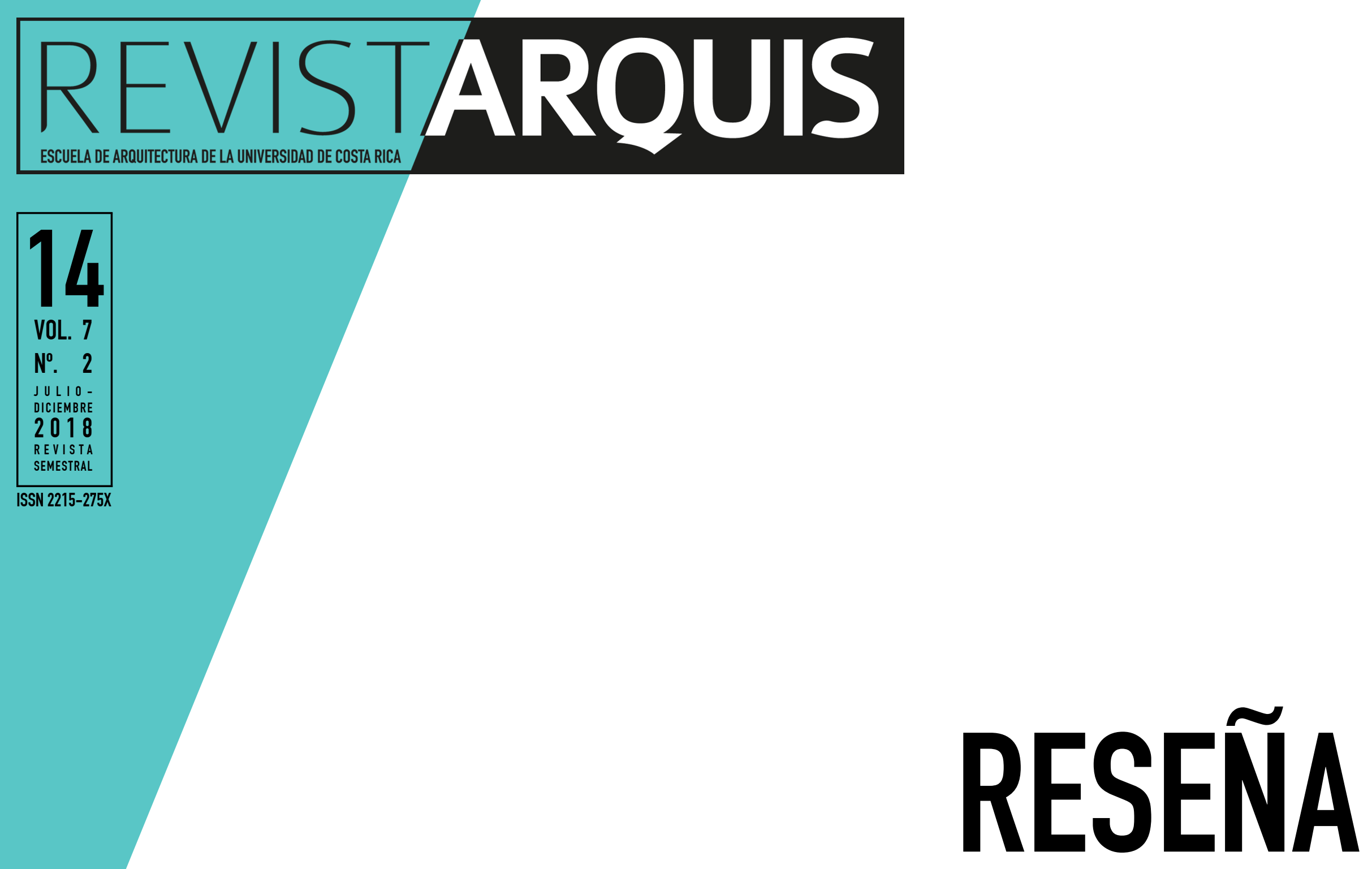

REVIEW

Imaginario urbano de la Ciudad de México en los Siglos XIX y XX

Annette Marín Guzmán y Andrés Quirós Villalobos | 113-125

Teatro Regional del Bío-Bío: cuerpo, espacio y movimiento

Hernán Barría Chateau | 126-130

\title{
Refugio Tropical
}

Triana Serrano Jlménez | 131-138

Museo Santuario

Julio Bonilla López | 139-150 


\title{
Imaginario urbano de la Ciudad de México en los Siglos XIX y XX
}

\author{
Annette Marín Guzmán \\ Andrés Quirós Villalobos
}

Reseña

Invitados nacionales

Estudiantes: Annette Marín Guzmán y Andrés Quirós Villalobos

Institución: Universidad de Costa Rica

Unidad Académica: Escuela de Geografía

E-mail: mannette92@gmail.com

E-mail: andresquiroscr@gmail.com

Recibido: 14 de mayo del 2018

Aprobado: 20 de junio del 2018

\section{Resumen:}

Se reseña el trabajo curatorial "Ciudad Imaginaria: Arquitectura mexicana de los siglos XIX y XX en fotografías de Luis Márquez Romay", desde una perspectiva geográfica que busca comprender las imágenes de diferentes paisajes urbanos retratados. Por medio de la identificación de los edificios, se encontró una relación entre el centro de la ciudad, el centro colonial, con los periodos de construcción, la distancia con respecto a dicho centro, los estilos arquitectónicos y los usos de las edificaciones los cuales se abordan a través del contexto histórico de la ciudad.

Palabras clave: arquitectura mexicana; Ciudad de México; fotografía; geografía urbana; imaginario urbano.

\section{Urban imaginary of the City of Mexico in the XIX and XX Centuries}

\section{Abstract:}

The curatorial work "Ciudad Imaginaria: Arquitectura mexicana de los siglos XIX y XX en fotografías de Luis Márquez Romay", allowed the analysis of the urban imaginary of Mexico City with a geographical perspective based on the images of Mexican urban landscapes. From the identification of urban symbols, a correlation was found between the center of the colonial city where the square functions as a starting point with the construction period, distance from the center, architectural style and uses, which are explained through the historical context of the city.

Keywords: mexican architecture; Mexico City; photography; urban geography; urban imaginary.

\section{Annette Marín Guzmán}

Estudiante de la Escuela de Geografía de la Universidad de Costa Rica.

\section{Andrés Quirós Villalobos}

Estudiante de la Escuela de Geografía de la

Universidad de Costa Rica. 


\section{Apertura}

a ciudad es entendida, desde la Geografía Urbana, desde una trialéctica, es decir, la interacción conjunta e inseparable de tres elementos principales, a saber: las materialidades, las experiencias y las representaciones o imaginarios (Harvey, 1998). Este último elemento toma relevancia para la presente reseña, ya que se pretende abordar el imaginario urbano de la Ciudad de México en los siglos XIX y XX. Para esto se toma el material fotográfico del trabajo curatorial "Ciudad Imaginaria: Arquitectura mexicana de los siglos XIX y XX en fotografías de Luis Márquez Romay", que fue expuesto como parte del ciclo de exposiciones "Historia, Ciudad y Arquitectura". La actividad fue organizada por el Laboratorio de Ciudad y Territorio de la Escuela de Arquitectura de la Universidad de Costa Rica y por el Centro de Estudios Mexicanos Costa Rica de la Universidad Nacional Autónoma de México.

La muestra, expuesta durante el mes de abril, estuvo compuesta por más de treinta imágenes que representan varios escenarios tanto de la Ciudad de México, como de Monterrey, Guadalajara, Saltillo, Guanajuato y Oaxaca. Las fotografías tienen el común denominador de representar o construir un imaginario urbano a partir de la arquitectura, imaginario que encarna un testimonio ideológico y cultural de México durante el siglo XIX y la primera mitad del siglo XX. A continuación, se realiza un breve análisis de las fotografías de Márquez Romay, especialmente las fotografías sobre la Ciudad de México ya que son las de mayor presencia en la exposición. La conceptualización del imaginario urbano se realiza a partir de una aproximación espaciotemporal de las estructuras y del contexto socioeconómico del país durante el tiempo de estudio.

\section{Contexto socioeconómico de la Ciudad de México, Siglos XIX y XX}

Los contextos históricos son agentes productores y formadores de los imaginarios urbanos, que en otras palabras significa entender que los contextos moldean los procesos de construcción social del espacio urbano (Lindón, 2007). Por esta razón en especial, son relevantes los contextos socioeconómicos en el que se desarrollan las ciudades, precisamente porque son la condición de posibilidad de los imaginarios. Además, son los mismos grupos de poder político y económico los que, en ocasiones, crean y circulan determinados imaginarios gracias a la utilización de medios para representarse a ellos mismos como los triunfadores (Araya, 2002).

En el siglo XIX México, luego de su independencia en 1821, se sumió en luchas internas e invasiones. A mediados de este siglo, Benito Juárez triunfa después de la guerra civil, restituyendo un proyecto de República Federal, proyecto liberal, que hace una reflexión sobre las bases históricas mexicanas negando el pasado indígena y el catolicismo colonial. Sin embargo, no tuvo mucho éxito debido a diversas presiones sociales. En este periodo no hubo cambios significativos en la Ciudad de México, manteniéndose la estructura urbana colonial que fue heredada de la época española.

Fue hasta el inicio del mandato de Porfirio Díaz que la ciudad se transforma abruptamente. Díaz permaneció en el poder por 30 años, las ideas de orden y progreso acompañadas de una estabilidad militar, política y social además de una solvencia económica propiciaron que la Ciudad de México se convirtiera en un escenario de grandeza y prosperidad. Se siguieron los ideales de la burguesía francesa, y la aristocracia se fue convirtiendo en una clase urbana "civilizada y culta".

Sánchez (2013) hace un recuento sobre cómo cambió la ciudad durante el porfiriato:

Las calles de la traza colonial se abren y se prolongan para enfatizar las perspectivas urbanas y dar cabida a la circulación del aire y de vehículos. Otro signo de modernidad es el impulso o consolidación de las redes de transporte que comunican a la ciudad consigo misma y con otros pueblos periféricos, estados de la República o países. (p. 3) 
Este momento tuvo una fuerte influencia del movimiento tanto positivista de transformación como moralista autoritario. Un proyecto de importancia en este periodo fue el desagüe y saneamiento de la ciudad de acuerdo con las normas higienistas del mundo europeo. Estos planes no solo buscan mejorar las condiciones de salubridad, sino que simbolizaron los procedimientos estatales de expulsión de la "inmundicia" de la ciudad, generalmente asociada a las clases populares. Estas iniciativas de modernización de la ciudad se plasmaron en planos, que también formaron parte también del proyecto racional y político de ordenar la ciudad.

En los planos de las Figura 1 y Figura 2, se puede ver como la ciudad en este periodo se desarrolla de forma ordenada, siguiendo las premisas que se expusieron anteriormente. Según Sánchez (2013) se aprecia en los planos dos características propias de una metrópoli: red de transporte diversos (servicios urbanos, sistema caminos, calles y avenidas) y una organización política y administrativa bajo control del Estado. En los planos se nota, asimismo, el crecimiento urbano con el cambio en los usos de suelo de las zonas rurales cercanas a la ciudad, que se fueron convirtiendo en fraccionamientos y luego en estos intensificaron las actividades urbanas.






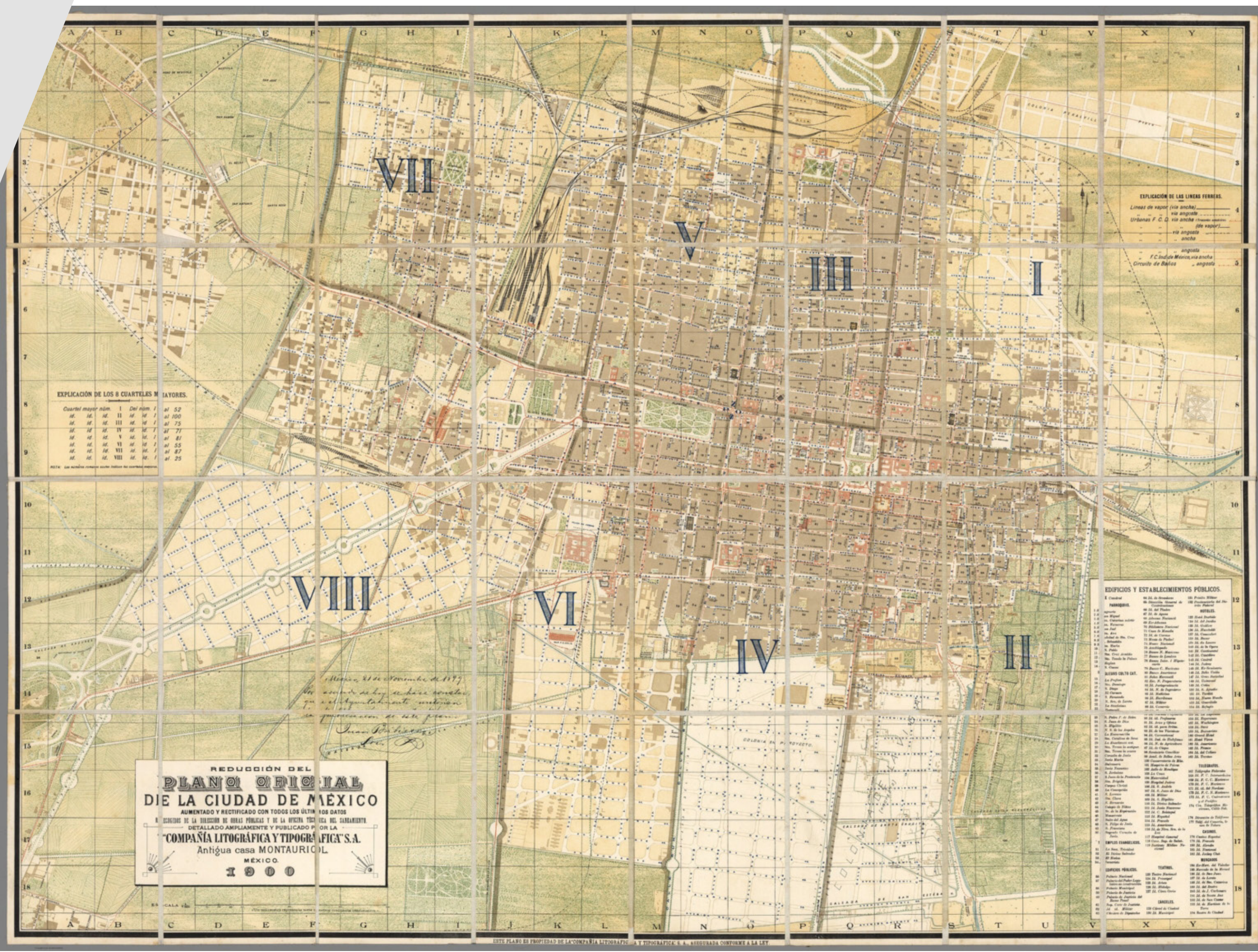

Figura 2. Plano oficial de la Ciudad de México 1900. Fuente: Mapoteca Orozco y Berra, publicado por Sánchez, 2013
En 1910 estalla la Revolución Mexicana, propiciada principalmente por la desigualdad social en el país. Estos conflictos tuvieron un impacto considerable en la hoy Ciudad de México. La revolución tuvo un carácter universal, un redescubrimiento del país desde una las esferas culturales e intelectuales que enfrentaron las posiciones positivistas del porfiriato. Desde este nuevo paradigma, en la Ciudad de México se crearon instituciones como el Colegio de México, etapa que estuvo apoyada, además, por un rico movimiento artístico que se materializó en monumentos como el Monumento a la Raza, y en embellecimiento de avenidas importantes en la ciudad.

A mediados del siglo $X X$, en el México posrevolucionario, una nueva ola de inversión estatal alienta la construcción de arquitecturas que representaron el progreso técnico, social y económico. En la década de los sesentas, las migraciones causan un crecimiento demográfico y espacial inaudito. La búsqueda de mejores condiciones por parte de la población campesina generó extensos anillos de miseria alrededor de la ciudad de México y, posteriormente, en su mismo centro histórico. 


\section{Imaginario urbano y fotografía}

El estudio de la ciudad implica no sólo el análisis de las formas urbanas, sino también de los modos de vida y de las percepciones que las personas tienen de estos multisistemas sociales, culturales y económicos. Con respecto a esto, se desarrolla el estudio del imaginario urbano, cuyo concepto y técnicas de abordaje son múltiples. Tanto García Canclini (2007) como Hiernaux (citado por Zamudio 2012), coinciden en que los imaginarios corresponden a un conjunto de elaboraciones simbólicas en torno a valoraciones del espacio, con una temporalidad dada respecto a lo desconocido o imaginado. No obstante, una definición más completa es la que brinda Santamaría (2013):

El imaginario urbano desde una concepción socio cultural heterogénea amplia, al mismo tiempo que contrasta lo simbólico y lo real, es un lugar de elaboración de insatisfacciones, deseos y búsqueda de comunicación al interior de grupos sociales y entre grupos sociales, que se transmite con pretensión de verdad para representar mediante imágenes un sentimiento compartido que otorga identidad a los individuos que conforman una nación, a partir de elementos básicos como son la lengua, la raza y el territorio, constituyéndose en tradición cultural dentro de la modernidad. (p. 47)

A esta definición se le puede agregar otro elemento básico: la arquitectura. Esta es un componente principal del paisaje urbano que brinda una imagen específica de un periodo y de las ideas que lo acompañaron. Por tanto, en esta reseña el imaginario urbano de la Ciudad de México durante los siglos XIX y XX, se trata desde una perspectiva geográfica con el fin de comprender las imágenes de los diferentes paisajes urbanos retratados fotográficamente por Luis Márquez Romay.

Debido a que la principal fuente de información corresponde a las fotografías de Márquez Romay, debe tomarse en consideración que "la misma obra, en realidad cualquier estructura visible, puede servir de base a muy distintas construcciones visuales. Ello que pone en evidencia la complejidad y la capacidad constructiva del acto de mirar al mismo tiempo que contradice la creencia en la transparencia y objetividad de la técnica fotográfica" (Gastón, 2015, p. 16). Una imagen puede ser interpretada de distintas formas, tanto por la técnica del fotógrafo como por el bagaje del observador.

Para Gastón (2015) la fotografía arquitectónica implica un sistema en donde interactúan el arquitecto, fotógrafo y espectador. El arquitecto brinda todas las vistas posibles, a su vez el fotógrafo selecciona e intensifica dichas vistas en un juego visual donde el espectador tiene una participación más activa. Por tanto, las fotografías de los elementos urbanos permiten acercar la ciudad y su imaginario a espectadores virtuales, así como a sus propios habitantes, presentes y futuros. Por esta razón, la construcción social de los distintos lugares que integran la ciudad conforma un proceso constante de manufacturación del espacio que realizan diferentes personas en interacción unas con otras.

La exposición "Ciudad Imaginaria: Arquitectura mexicana de los siglos XIX y XX en fotografías de Luis Márquez Romay", contó con más de treinta imágenes, en las cuales se identificaron 29 edificaciones distintas localizadas en su mayoría en la Ciudad de México, aunque también se encontraron estructuras de Monterrey, Guadalajara, Saltillo, Guanajuato y Oaxaca. No obstante, se hará énfasis en dos zonas de importancia debido a la concentración de edificios con características arquitectónicas e históricas relevantes. El primero es el corredor que va del Centro Histórico de la Ciudad de México y el Bosque de Chapultepec, conectados mediante el Paseo de la Reforma. Y el segundo es el campus de la Universidad Nacional Autónoma de México (UNAM). Sus ubicaciones se muestran en el mapa de la Figura 3. 




Figura 3. Mapa de la Ciudad de México y las zonas de interés por aglomeración

de estructuras. Fuente: Elaboración propia, 2018
Ambos sectores se localizan en la entidad federativa de la Ciudad de México, que conforma a su vez la capital del país. Las áreas de estudio son relevantes no sólo en el análisis del imaginario urbano de la ciudad, sino que a su vez son representaciones de la identidad nacional del pueblo mexicano. La ciudad demuestra, a lo largo de la historia, ser un medio para expresar la exaltación identitaria de lo sagrado y secular, convirtiéndose con el tiempo en un símbolo de lo posible (Zambrano, 2002). Su distribución se muestra en el mapa de la Figura 4.

Según el Instituto Nacional de Estadística y Geografía (INEGI), para el 2015 en la Ciudad de México habitaban 8,985,339 personas, lo que representa una densidad poblacional de 5,967.3 hab/ $/ \mathrm{km} 2$. No obstante, el proceso de conurbación ha consolidado el espacio conocido como Área Metropolitana del Valle de México, el cual incluye las 16 delegaciones de la Ciudad de México además de 60 municipios del Estado de México e Hidalgo, en donde según el censo del 2010, realizado por el INEGI, era habitado por más de 22 millones de personas. Por otro lado, durante el ciclo 2017-2018 la población de la UNAM es de 349.515 estudiantes y 40.578 académicos (Portal de Estadística Universitaria, 2017). 


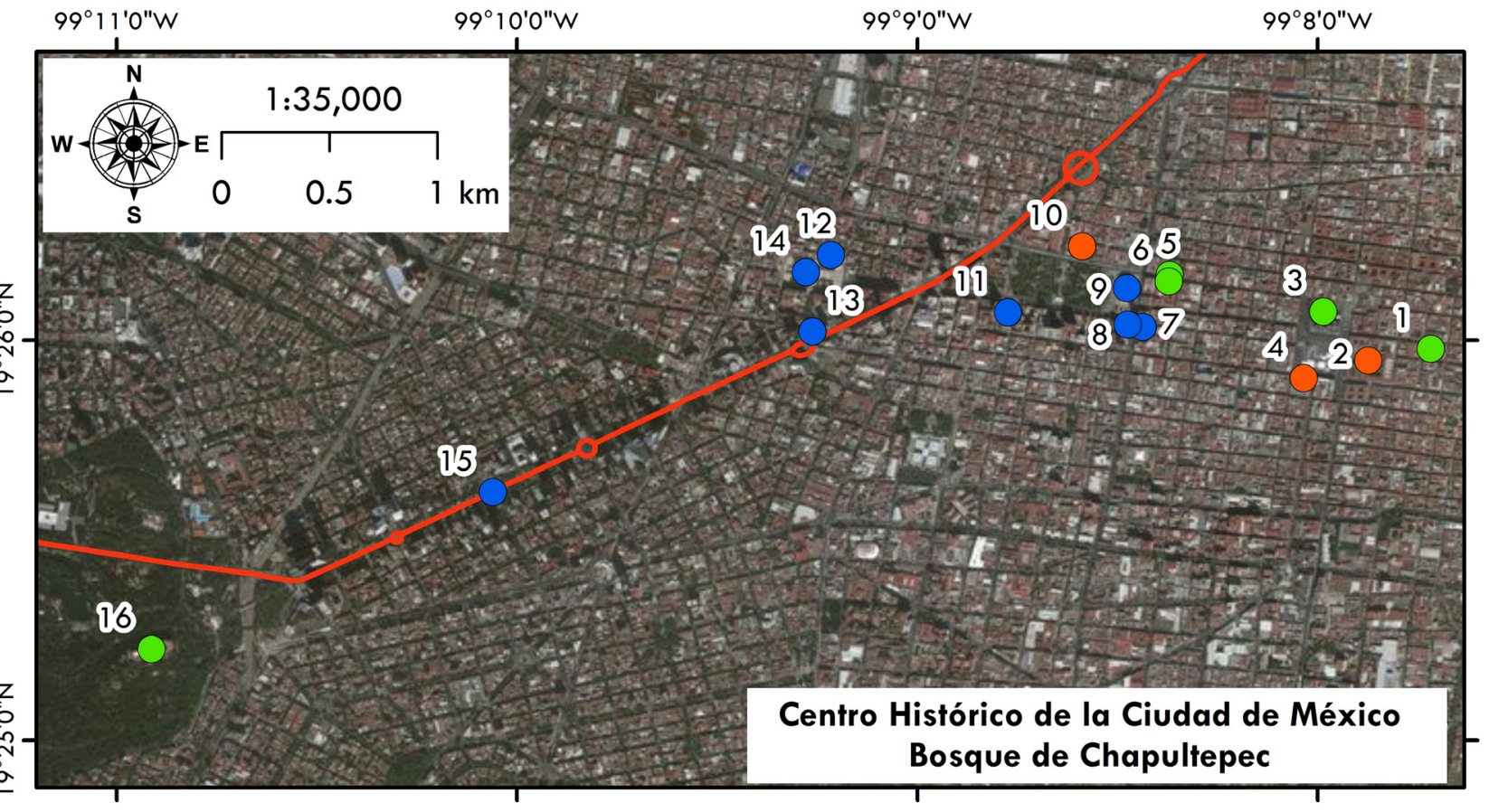

\section{CIUDAD DE MÉXICO}

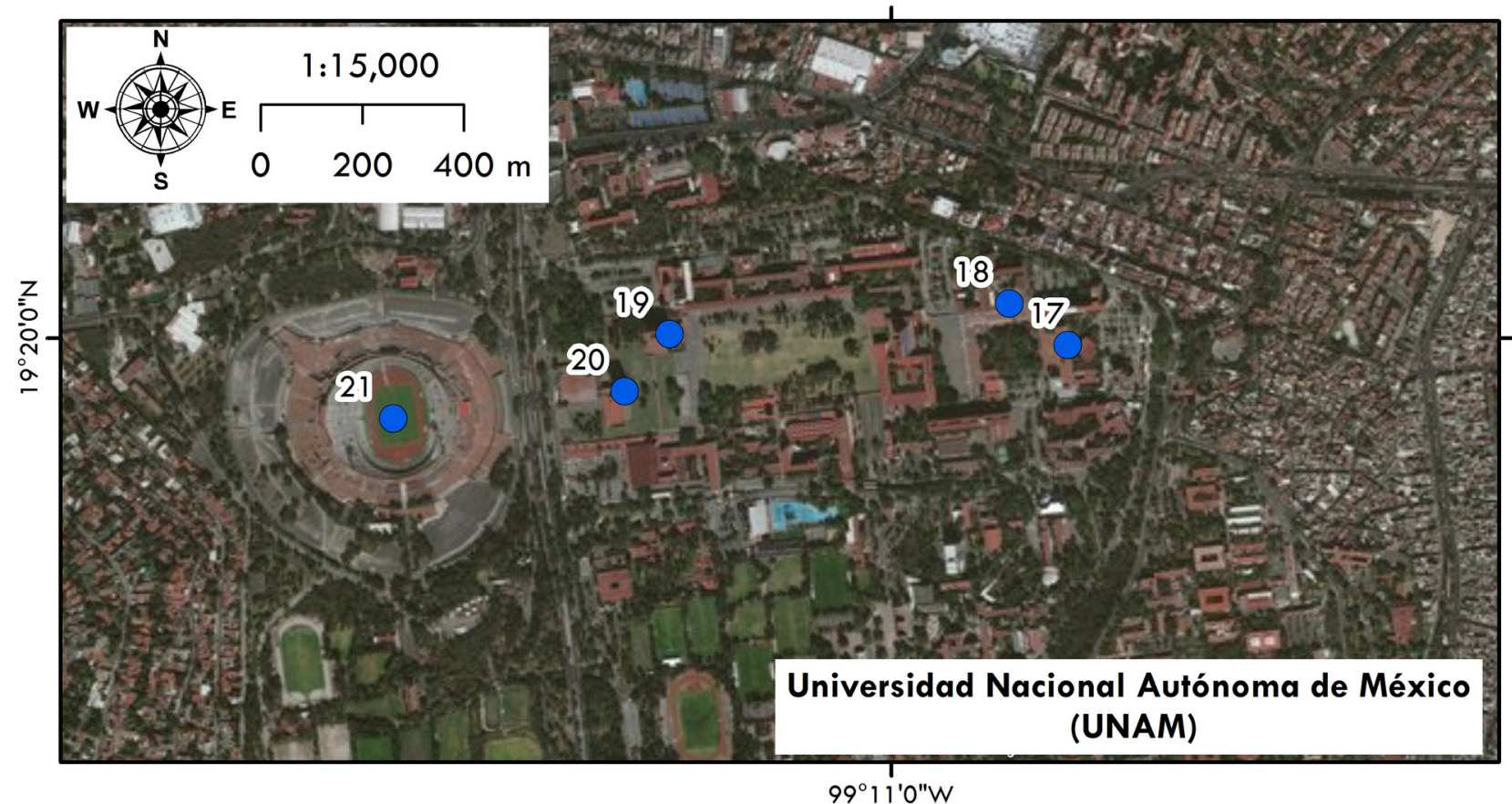

\section{Simbología}

Época de construcción

Siglo XVI

Siglo XVIII - Siglo XIX

Siglo $X X$

Paseo de la Reforma

Academia de San Carlos

Palacio Nacional

Catedral Metropolitana

Departamento del Distrito Federal

Estatua ecuestre de Carlos IV

Palacio de Minería

Torre Latinoamericano

La Nacional Compañía de Seguros

Palacio de Bellas Artes

Hospital San Juan de Dios (Museo

Franz Mayer)

Hotel del Prado

Frontón México

Secretaría de Recursos Hídricos

Monumento a la Revolución

Monumento a la Independencia

Castillo de Chapultepec

Facultad de Medicina

Pabellón de Rayos Cósmicos

Biblioteca Central

Rectoría

Estadio Olímpico

Proyección WGS84

Autor: Marín, 2018

Figura 4. Mapa de localización de las estructuras de interés en la Ciudad de México. Fuente: Elaboración propia, 2018

\section{A Corredor: Centro Histórico - Paseo de la Reforma - Bosque de Chapultepec}

Esta área de estudio contiene 16 edificios de los 21 en estudio. La mayor concentración se encuentra en el Centro Histórico de la Ciudad de México, que corresponde al centro original de la ciudad, cuya influencia colonial es notoria debido a la presencia de una plaza central, en este caso El Zócalo o Plaza de la Constitución, así como un trazado ortogonal en las zonas aledañas. Según su año de construcción, las estructuras en estudio pueden ser clasificadas en tres grupos: siglo XVI, finales del siglo XVIII e inicios del siglo XIX y las estructuras de la primera mitad del siglo XX.

El primer grupo congrega al Palacio Nacional, edificios sede del Departamento del Distrito Federal y el Hospital San Juan de Dios actualmente Museo Franz Mayer (Anexo 1). Su construcción remonta a los inicios del Virreinato de Nueva España, por lo que se encuentran influenciados por el estilo Barroco y Barroco Mexicano, el cual se caracteriza por la existencia de un patio central. Asimismo, en este caso debido a su uso administrativo y militar, los edificios presentan tipología de fortaleza, con torres en las esquinas y fachadas sobrias decoradas con ventanas y arcos de forma repetitiva y ordenada. Particularmente el Palacio Nacional y los de uso federativo son símbolos del poder político de la ciudad, que se mantienen hasta la actualidad.

El segundo grupo corresponde a las estructuras construidas entre finales del siglo XVIII e inicios del siglo XIX. En este periodo se encuentran cinco edificios, entre los que resaltan la Catedral Metropolitana, La Academia de San Carlos y el Castillo de Chapultepec, los cuales mantienen el estilo barroco, aunque también se tiene obras de estilo neoclásico y renacentista (Anexo 2). En este periodo toma importancia la figura de Manuel Tolsá, arquitecto e ingeniero español que tuvo a cargo varias de las obras más representativas de la época (Vázquez, 2017). Sus obras se mantienen en el ámbito 
Anexo 1. Departamento del Distrito Federal, Palacio Nacional. Foto por: Luis Márquez Romay del control político y el forjamiento de la identidad cultural de la ciudad, a partir de la estatua ecuestre de Carlos IV y el Palacio de Minería; no obstante, resalta la Catedral Metropolitana, ya que este a partir del uso de variados estilos arquitectónicos como el gótico, barroco, churrigueresco y neoclásico representan el nuevo orden religioso de la sociedad mexicana, el cual se mantiene hasta hoy en día, con una importante influencia católica ya que más del 89\% de la población profesa dicha religión (INEGI, 2010).
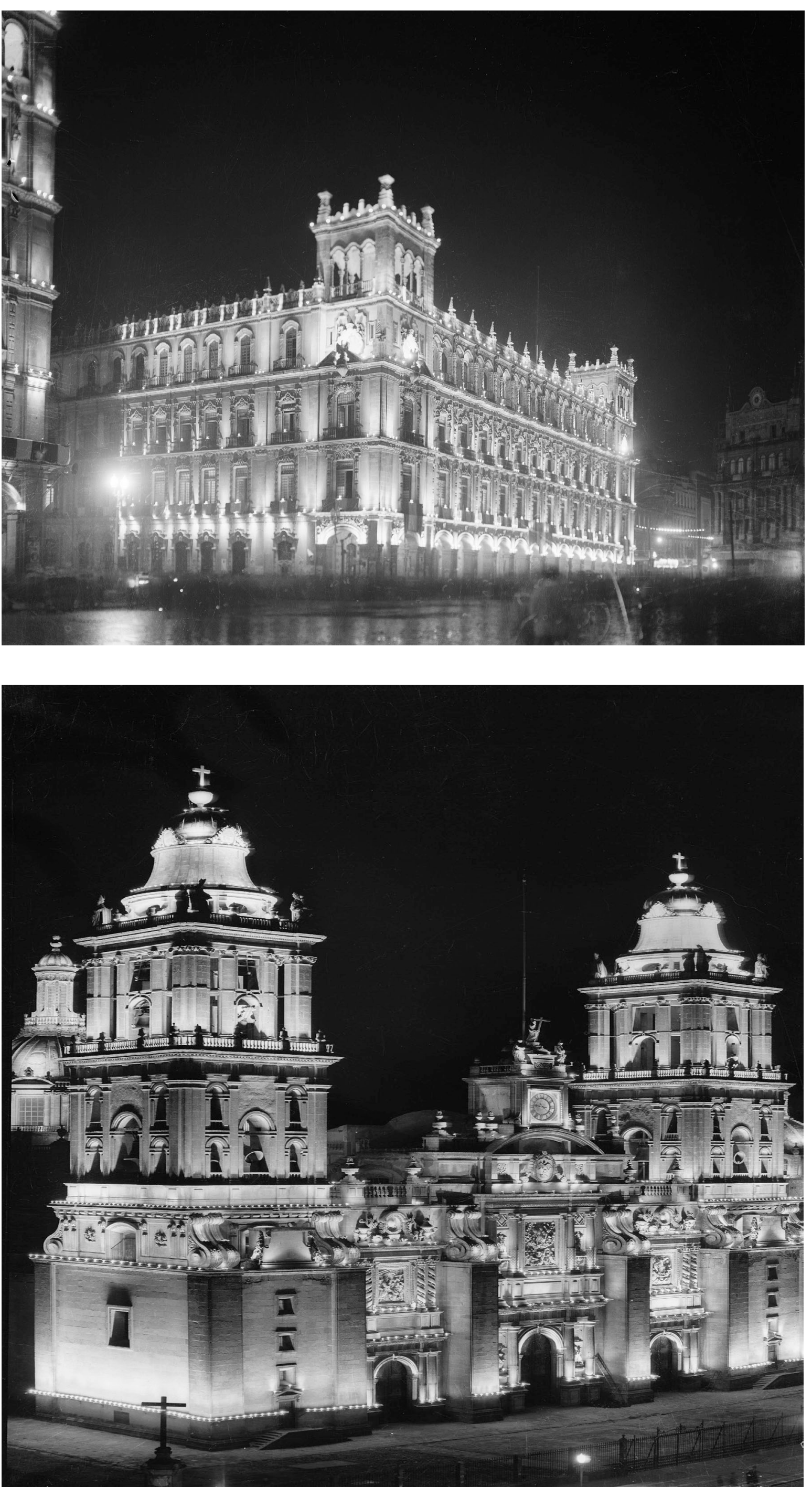
Anexo 2. (b) Academia de San Carlos. Foto por: Luis Márquez Romay

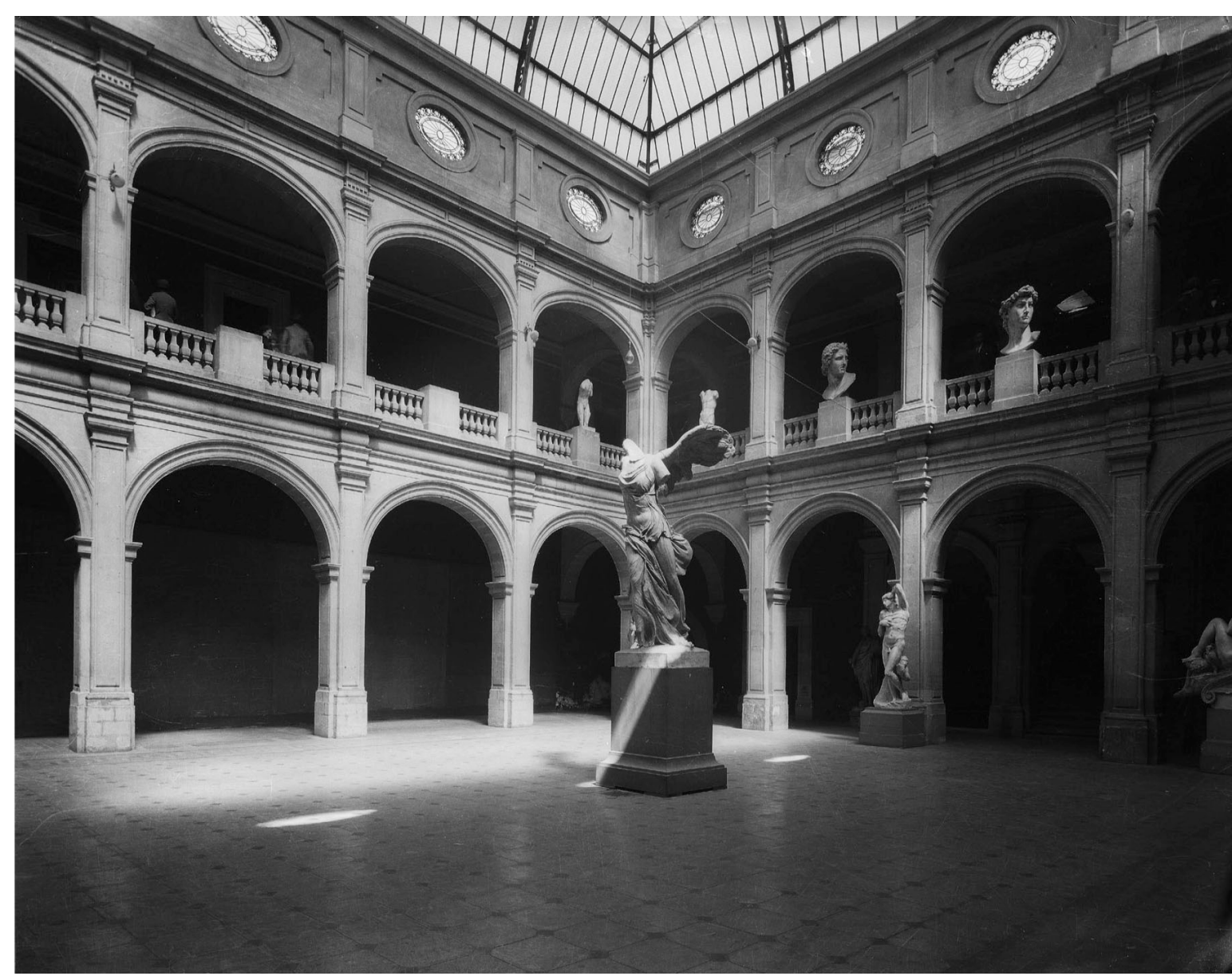

Por último, se tienen las edificaciones de la primera mitad del siglo XX, estas son las más numerosas con ocho construcciones, entre las que se encuentran el Monumento a la Independencia, el Palacio de Bellas Artes y la Torre Latinoamericana (Anexo 3). Se encuentra totalmente influenciado por el movimiento moderno, así como el Art Decó y los últimos vestigios del neoclásico. Este periodo busca la renovación de la ciudad, su estilo arquitectónico contrasta con su pasado colonial. Estas estructuras tienen una mayor influencia americana, resaltando sus características estilizadas y simétricas, haciendo uso de las figuras geométricas y manejo de volumen (Mattos, 2002). Los usos de las estructuras cambian, ya que no sólo representan símbolos políticos o religiosos, sino también comerciales, como por ejemplo el Hotel del Prado, Frontón México y la Torre Latinoamericana, que representan a la ciudad como un hito económico y cultural. La Torre Latinoamericana, con su tipología de rascacielos y estructura de acero, es un símbolo de la modernización del siglo XX, de la ciudad como máquina, siempre activa y en constante crecimiento, que trata de asemejar el paisaje de las principales urbes americanas como lo es Nueva York.

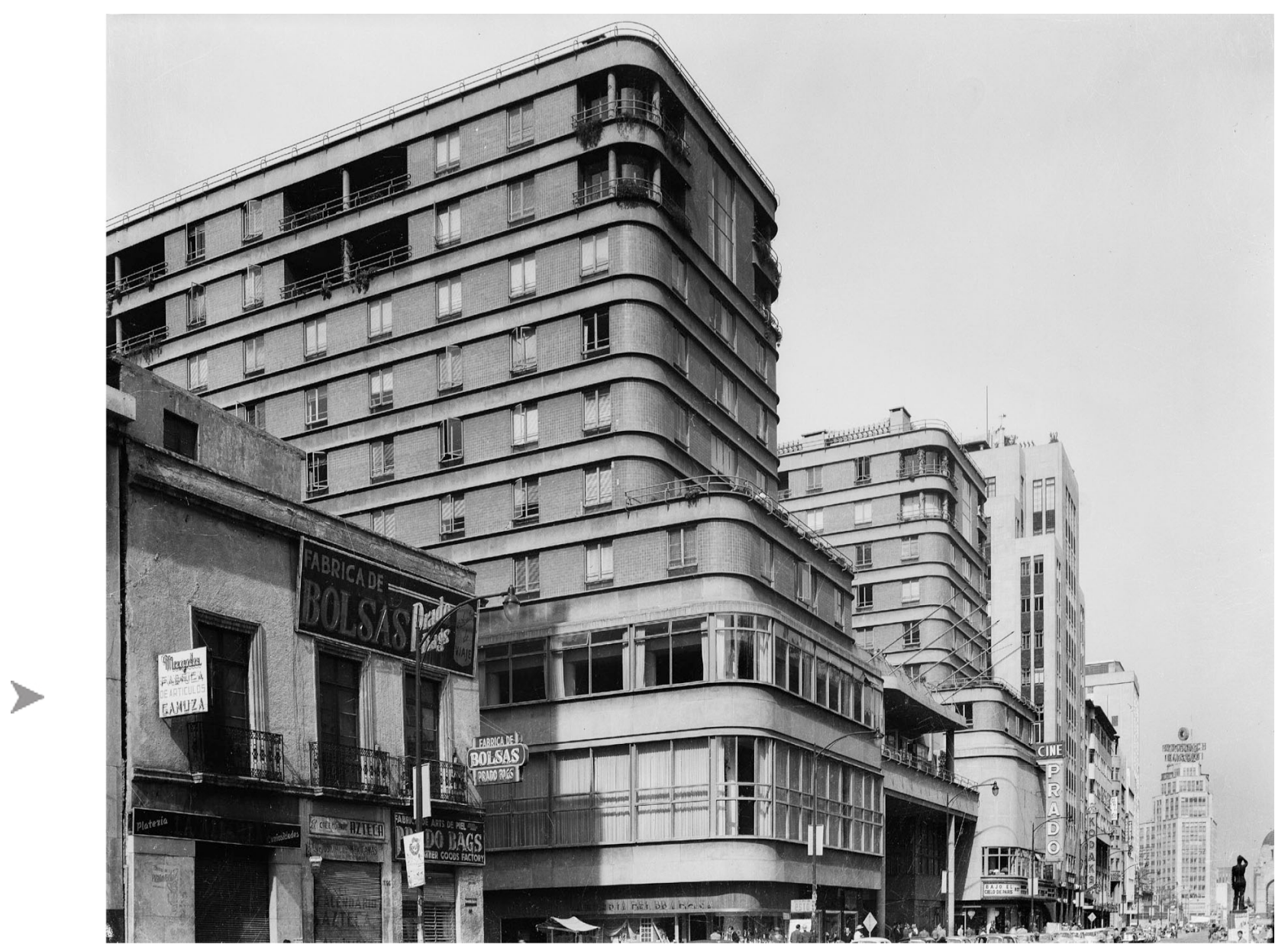


Anexo 3. (b) Torre Latinoamericana. Foto por: Luis Márquez Romay

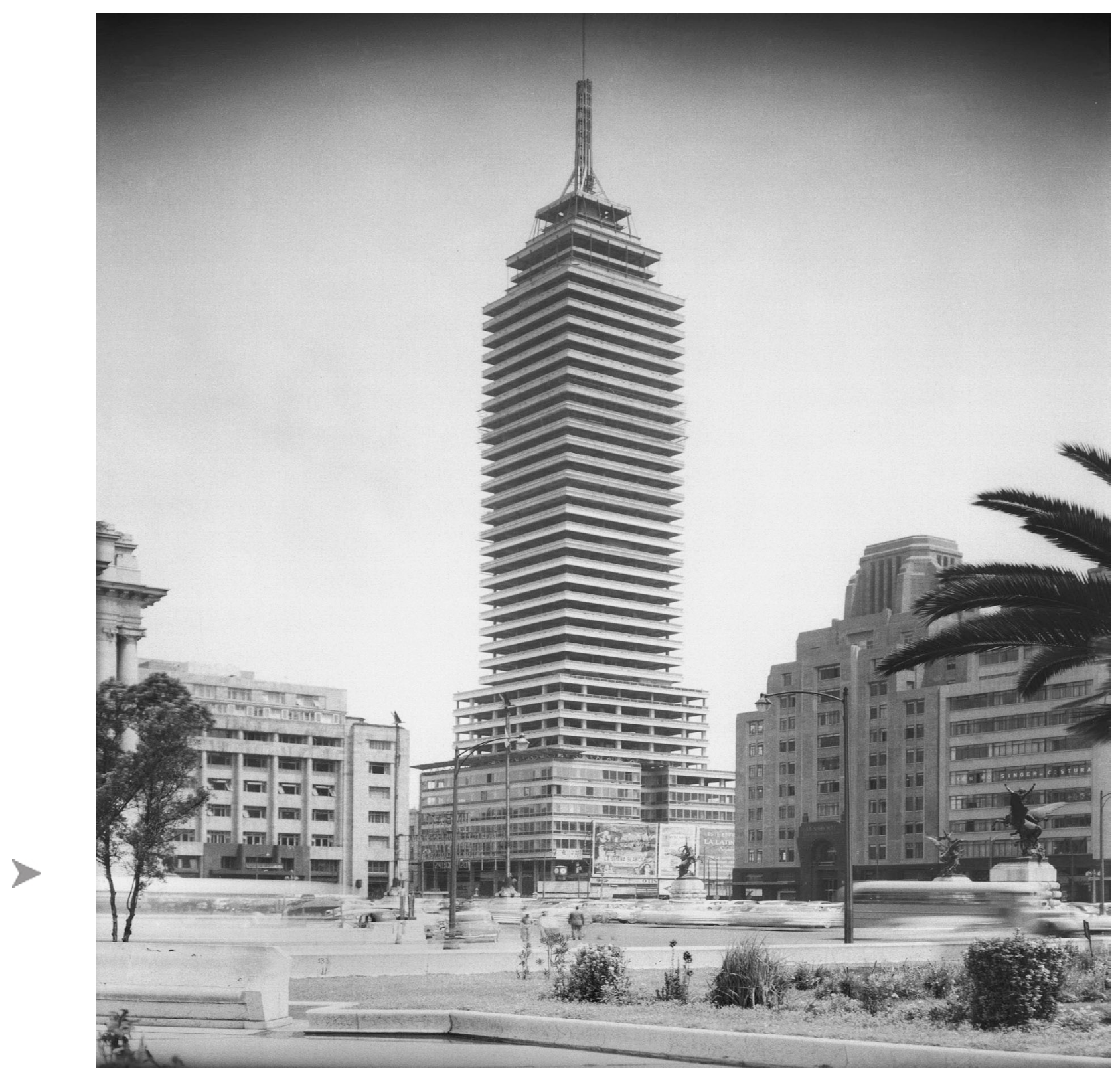

\section{Campus de la Universidad Nacional Autónoma de México}

Esta segunda aglomeración de edificaciones mantiene la línea arquitectónica del movimiento moderno. En esta área se identificaron cinco inmuebles. Estos fueron construidos durante la primera mitad de los años cincuenta del siglo pasado. Las estructuras integran una arquitectura sencilla, de líneas rectas y funcional con las bellas artes y el pasado prehispánico de México (UNESCO, s.f.). Por ejemplo, Márquez Romay retrató los murales de Francisco Eppens, Juan O'Gorman y Diego Rivera, que cubren por completo las fachadas de los edificios y evocan temas de la cultura prehispánica. Además, se encuentra una de las obras del arquitecto e ingeniero Félix Candela, como lo es el Pabellón de Rayos Cósmicos, que fiel al estilo de su autor muestra forma de paraboloide que le permiten el uso de losas de concreto delgadas y de líneas fluidas (Anexo 4).
Anexo 4. (a) Pabellón de Rayos Cósmicos, UNAM. Foto por: Luis Márquez Romay. (b) Estadio Olímpico, relieve de Diego Rivera UNAM,

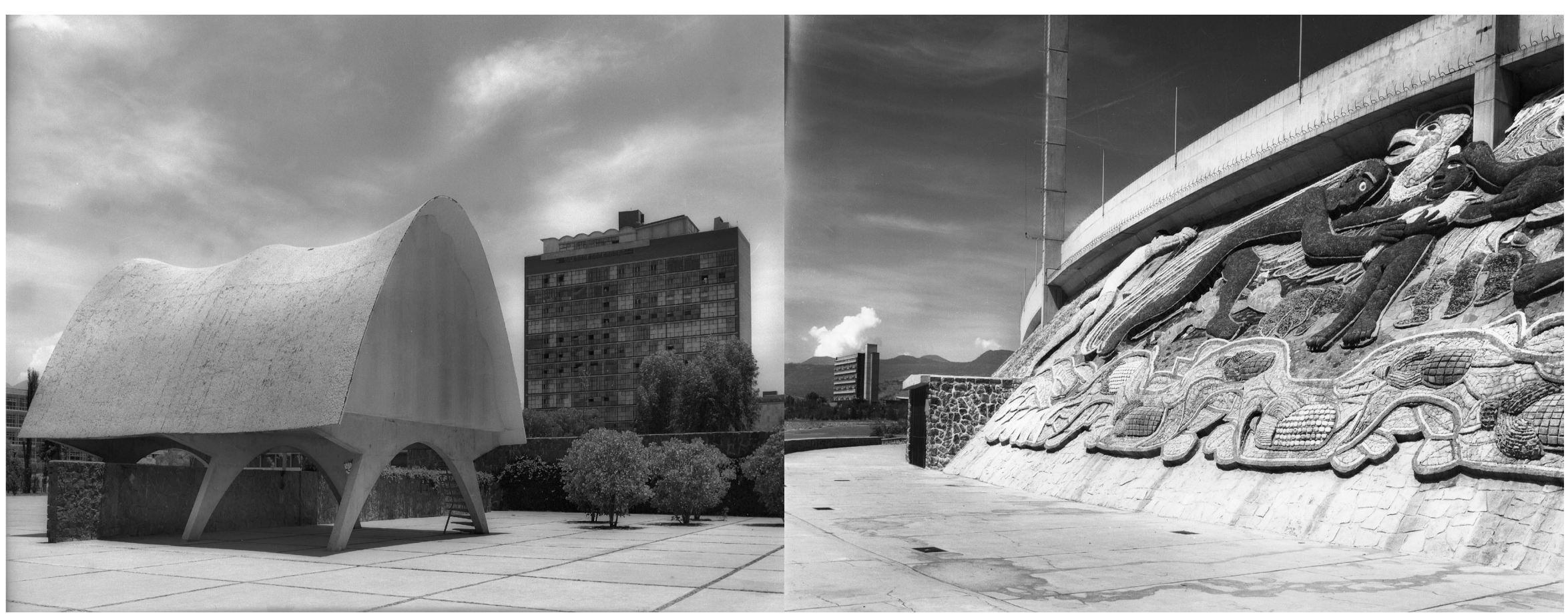




\section{Análisis espacial del imaginario urbano}

A partir del mapeo de la localización de las estructuras de estudio, es evidente la concentración de estas en las dos principales áreas antes mencionadas. Esto quiere decir que el imaginario presentado por Márquez Romay cubre un área geográfica relativamente pequeña. Sin embargo, la monumentalidad y simbolismo de las estructuras hacen de estas un fiel reflejo de la evolución de los valores hegemónicos mexicanos. No obstante, es importante notar que las fotografías no muestran a las personas ni sus actividades, por lo que el imaginario puede estar limitado, en especial para las personas que no habitan o hayan visitado la ciudad.

Asimismo, se identificó una relación entre el periodo de construcción, el estilo arquitectónico y la distancia con el centro histórico, con un especial crecimiento hacia el Oeste. La plaza central (el Zócalo) marca el punto de partida de crecimiento de la ciudad desde el periodo colonial, por lo que es de esperar que las estructuras más cercanas mantengan relación con dicho periodo y con estilos arquitectónicos europeos en especial de influencia española, como el barroco. Seguidamente, a mayor distancia se encuentran los edificios de los siglos XVIII y XIX, donde el estilo barroco le abre paso al neoclásico, y por último el modernismo tiene un radio de influencia mucho mayor con respecto al centro.

La Torre Latinoamericana funciona como límite del centro histórico, el cual se evidencia con el aumento de edificaciones y monumentos de este periodo, en especial hacia el Oeste, siguiendo el Paseo de la Reforma, una de las vías de comunicación más importantes de la ciudad. Son este tipo de estructuras las que tienen una mayor área de influencia, por lo que podrían mostrar un mayor peso en la construcción social de la ciudad.

Esta disposición en el espacio de las estructuras y su época de construcción refleja el desarrollo urbano y social de la ciudad, tal como lo menciona Borsdorf (2003), un primer símbolo de la ciudad de origen colonial es la plaza, en este caso el Zócalo. El autor menciona:

La plaza mayor, denominada originalmente plaza de armas, constituía tanto el centro de cada ciudad como la estructura clave para la red de calles urbanas. Además, la plaza actuaba como el núcleo de la vida social. La posición social de cada uno de los ciudadanos estaba determinada por la distancia de su casa respecto de la plaza principal. La pendiente social y funcional desde el centro a la periferia se reflejaba en la estructura social circular de los barrios. Cerca de la plaza estaba instalada la aristocracia, formada por las familias de los conquistadores, los funcionarios de la corona y los encomenderos 0 grandes hacendados. El círculo siguiente era ocupado por la clase media, formada por comerciantes y artesanos. En este barrio se ubicaba por lo general el mercado municipal. En el último círculo, el más periférico, vivían los "blancos pobres", los indios y mestizos. (p. 40)

Seguidamente, se da una primera fase de urbanización en rupturas con un principio de linealidad, en donde se denota la importancia del Paseo de la Reforma, como eje conector entre el centro y el Castillo de Chapultepec. Borsdorf recuerda que:

El cambio político-económico causó-con un cierto retraso-la reestructuración del organismo urbano, ante todo en lo relativo a la estructura social y económica... De Europa provenían además las modas urbanísticas, como el boulevard francés de la época de Haussmann, denominada alameda, paseo o prado, y la villa europea. El principio de estructuración espacial más típico de esta época es la diferenciación sectorial orientada a estructuras lineales. En el modelo, este principio se evidencia claramente en el crecimiento de los sectores de la clase alta, que se orientó al boulevard principal, y en el desarrollo de las primeras zonas industriales, establecidas cerca de las líneas ferroviarias que conectaban la ciudad con el resto de cada país. (2003, p. 42)

El modelado del crecimiento de las ciudades latinoamericanas evidencia una segunda fase de urbanización orientada a la polarización entre clases sociales, en este respecto el trabajo de Márquez Romay no muestra mucha distinción de quién hace uso de los espacios, no obstante, edificios como el Frontón México representan un sitio donde las clases sociales se acercaban en torno al deporte de pelota vasca. Es hasta este periodo que las fotografías tienen alcance en el estudio del imaginario, debido a su 
periodo de captura. No obstante, es evidente que la Ciudad de México ha alcanzado un estado de fragmentación con la creación de barrios cerrados y centro comerciales, en especial hacia la periferia de la ciudad; sin embargo, esto queda fuera del periodo de estudio.

Por su parte, la ciudad universitaria de la UNAM renueva la imagen de la ciudad con edificios de estilo moderno, no obstante, pretende mantener vivo en el paisaje el pasado prehispánico y la cultura indígena. Por lo tanto, promueve símbolos importantes para el imaginario urbano, como lo es el rescate del arte y de los elementos históricos, en contraposición a las corrientes de la cultura liberal y la exaltación por lo europeo. Cabe destacar que este espacio no es tan visitado en comparación con el anterior por los propios habitantes de la ciudad, debido a que, al ser un campus universitario, las personas que lo transitan con más frecuencia suelen ser estudiantes y académicos, pero esto no desmerita estas estructuras como parte de la construcción del imaginario de la ciudad.

\section{Cierre}

Aproximarse a la ciudad, sin importar el tipo de estudio, implica hacer estudios históricos para comprender cómo esta se forma y se transforma. Por eso, el estudio de la historia de la ciudad debe comprender los aspectos sociales y económicos ya que son estos los que se plasman en los componentes físicos de la ciudad (infraestructura, red vial, etc.) y los que configuran espacios.

En la ciudad de México, los factores políticos han sido responsables de las transformaciones urbanas desde el siglo XIX, empezando con una formación de ciudad que rechaza su pasado colonial y su realidad indígena que buscan imponer un modelo de orden, progreso ajeno y tecnicista. Con la revolución mexicana se rechaza el modelo anterior y se busca redescubrir México; entre 1910 a 1940 la Ciudad de México apoyada por movimientos artísticos se llena de símbolos que representan ese redescubrir de México. Para la segunda mitad del siglo XX el país se enfrenta a problemas de pobreza y desigualdad que provocan migraciones hacia la ciudad creando anillos de miseria.

Este contexto histórico es plasmado en la arquitectura y en las fotografías de Luis Márquez Romay. Sus retratos muestran las principales estructuras que conforman el imaginario social, político, cultural y económico de la ciudad, no obstante, este se ve limitado al extraer la figura humana y sus actividades de la imagen. Sin embargo, su trabajo permite comprender la evolución de la ciudad y analizar el paisaje urbano de los siglos pasados. Por ejemplo, resalta la fotografía del Hotel del Prado (Anexo 3), construido en 1948 como un ícono del estilo Art Decó, sin embargo, este fue demolido en 1985 debido a los daños sufridos por un terremoto ese mismo año, lo que hace evidente la transformación del paisaje y por tanto del imaginario, en especial de las generaciones presentes y futuras. Por tanto, los imaginarios se encuentran en constante transformación, con colectivos e individuales y brindan información sobre la ciudad imaginada, desconocida, los estilos de vida de "los otros" y de los propios.

El imaginario del siglo XIX y siglo XX se encuentra marcado por la secularización cultural, con una vocación comercial, donde en el espacio y la arquitectura reflejan la paradoja colonialidad-modernidad. La Ciudad de México se muestra como un espacio de evolución, con un pasado colonial todavía presente en la morfología urbana, la cual ha condicionado la cultura del pueblo mexicano, por ejemplo, la religión. Sin embargo, el orden del damero se vuelve caos con el crecimiento descontrolado de la ciudad. El poder político y administrativo se expone en estructuras amuralladas, decoradas con estilo español. La ciudad moderna es de metal y vidrio, con líneas sencillas y predominancia de formas geométricas elegantes.

Pero, finalmente, la Ciudad de México es heterogénea, ya que la conforman más de 22 millones de imaginarios. 


\section{Referencias Bibliográficas}

Araya, M. (2002). Miedos de comunicación e imaginarios urbanos en San José. Vínculos, 27, 141-165.

Borsdorf, A. (2003). Cómo modelar el desarrollo y la dinámica de la ciudad latinoamericana. EURE, 29(86), 37-49.

Gastón, C. (2015). El modo en que miramos. Fotografía como arquitectura. Click 1, 1419. Recuperado el 6 de Mayo de 2018, de https://pa.upc.edu/ca/novcat/click_dpa. pdf

Harvey, D. (1998). La condición de la posmodernidad: investigación sobre los orígenes del cambio cultural. Barcelona, Amorrotu.

INEGI. (2015). México en cifras. Recuperado el 8 de Mayo de 2018, de Instituto Nacional de Estadística y Geografía: http://www.beta.inegi.org.mx/app/areasgeograficas/ default.aspx

Lindón, A. (2007). Diálogo con Néstor García Canclini: ¿Qué son los imaginarios y cómo actúan en la ciudad? EURE, 33(99), 89-99.

Mattos, M. (2002). Del Art Nouveau al Art Decó. Tiempo, 46-53. Recuperado el 6 de Mayo de 2018, de http://www.uam.mx/difusion/revista/nov2002/demattos.pdf

Sánchez, M. (2013). La ciudad de México en la cartografía oficial del Porfiriato. Los planos oficiales de la ciudad de México de 1981 y 1900. Una visión de la metrópoli. Seminario Internacional de Investigación en Urbanismo. "V Seminario Internacional de Investigación en Urbanismo, Barcelona-Buenos Aires, junio 2013", (págs. 240251). Barcelona. Obtenido de https://upcommons.upc.edu/handle/2099/14160

Santamaría, L. (2013). Imaginario, identidad y arquitectura. Contexto, 7(7), 43-51.

UNAM. (2017). Portal de estadística universitaria. Recuperado el 3 de Mayo de 2018, de La UNAM en números 2017-2018: http://www.estadistica.unam.mx/numeralia/

UNESCO. (s.f.). Campus central de la Ciudad Universitaria de la Universidad Nacional Autónoma de México. Recuperado el 5 de Mayo de 2018, de https://whc.unesco. org/es/list/1250

Vázquez, J. (2017). Las misiones de Manuel Tolsá. Casa del Tiempo, 37(42), 4347. Recuperado el 3 de Mayo de 2018, de http://www.uam.mx/difusion/ casadeltiempo/37_feb_2017/casa_del_tiempo_eV_num_37_42_47.pdf

Zamudio, L. (2012). La arquitectura en los imaginarios turísticos. Revista de Investigaciones Políticas y Sociológicas, 12(2), 145-158.

Zambrano, F. (2002). La ciudad en la historia. En: TORRES, C. (Comp.) La ciudad: hábitat de diversidad y complejidad. Bogotá, EUNAL. Pp. 122-148. 